\title{
EVALUATION OF INCIDENCE AND ACCURACY OF FNAC WITH HISTOPATHOLOGICAL FINDINGS IN THYROID NEOPLASMS: A DETAILED CASE STUDY
}

\author{
Dhamayanthi Suryamoorthy1, Rani Kalavathy², Revathi Ramakrishnan ${ }^{3}$ \\ ${ }^{1}$ Associate Professor, Department of Pathology, Theni Medical College, Theni. \\ 2 Professor, Department of Pathology, Theni Medical College, Theni. \\ ${ }^{3}$ Associate Professor, Department of Pathology, Theni Medical College, Theni.
}

\begin{abstract}
BACKGROUND

Recently, FNAC has become the investigation of choice in thyroid swelling or swelling thought to be of thyroid origin. The current study is an attempt to establish the role of FNAC as an important preliminary diagnostic tool in thyroid disease with particular attention to minimise false negative diagnosis in correlation with histopathological study.
\end{abstract}

\section{MATERIALS AND METHODS}

The present study was undertaken for a period of 3 yrs. from January 2002-December 2004. The cytological materials were obtained in the form of smears, which were fixed in 95\% alcohol for PAP and H and E staining. Specimens were received from Department of Surgery. Specimens were processed, sections were made, and stained with $\mathrm{H}$ and E. Special stains were used as and when required (Congo red for demonstration of amyloid in cases of medullary carcinoma).

\section{OBSERVATIONS AND RESULTS}

13,822 biopsy materials were received. Of these, the thyroid lesions accounted for 782 cases. Hence, the overall incidence of thyroid lesions are $5.65 \%$. The number of neoplastic thyroid tumours were 326 . Of these, 224 were benign (68.71\%) and 102 cases were malignant (31.28\%). While the benign thyroid tumours had a peak incidence in the third decade, the peak incidence of malignant thyroid tumours were seen in fourth decade. The youngest patient was 5 yrs. of old and the oldest patient was 89 yrs. of old. Of the 152 cases on which fine needle aspiration cytology was performed, histopathological correlation was possible only for 130 cases.

\section{CONCLUSION}

Most cases in the present study were in the $3^{\text {rd }}$ and $4^{\text {th }}$ decade and there is an obvious female preponderance comprising $89.5 \%$ of the total with a female:male ratio of 8.5:1.5. In our study, most of the patients complained of a thyroid swelling of less than 1 year duration. There was an excellent cytological correlation with histopathological study in cases of papillary carcinoma, thyroid (88.37\%), and anaplastic carcinoma (100\%). The current study has shown that in our centre FNAC has a sensitivity of $96.42 \%$ for benign lesions and $95.35 \%$ for malignant lesions. The accuracy for benign lesions is $92.72 \%$.

\section{KEYWORDS}

Thyroid Neoplasms, FNAC of Thyroid, Accuracy.

HOW TO CITE THIS ARTICLE: Suryamoorthy D, Kalavathy R, Ramakrishnan R. Evaluation of incidence and accuracy of FNAC with histopathological findings in thyroid neoplasms: a detailed case study. J. Evolution Med. Dent. Sci. 2016;5(62):4351-4355, D0I: $10.14260 /$ jemds/2016/993

\section{INTRODUCTION}

Recently, FNAC has become the investigation of choice in thyroid swelling or neck swelling thought to be of thyroid origin. The two fundamental requirements in which the success of FNAC depends are representativeness of the sample and high quality preparations. In addition, information obtained by FNAC must always be correlated with other investigations.

In this study, we statistically evaluating the incidence of neoplastic thyroid lesions to assess the usefulness of the cytological study and diagnosis of thyroid neoplasms evaluate the accuracy of the FNAC studies in correlation with histopathological study. ${ }^{1}$

Financial or Other, Competing Interest: None.

Submission 10-07-2016, Peer Review 25-07-2016,

Acceptance 27-07-2016, Published 03-08-2016.

Corresponding Author:

Dr. Dhamayanthi. $S$,

\#22/2, Srinivasa Street,

Krishnapuram Colony,

Madurai-625014.

E-mail: revathiram67@gmail.com

DOI: $10.14260 /$ jemds $/ 2016 / 993$

\begin{abstract}
MATERIALS AND METHODS
The present study was undertaken for a period of 3 yrs. from January 2002-December 2004. The cytological materials were obtained in the form of smears, which were fixed in $95 \%$ alcohol for PAP and $\mathrm{H}$ and $\mathrm{E}$ staining. Specimens were received from Department of Surgery. The specimens were fixed in $10 \%$ formalin. After paraffin embedding 5 micron thick sections were made and stained with $\mathrm{H}$ and $\mathrm{E}$. Special stains were used as and when required (Congo red for demonstration of amyloid in cases of medullary carcinoma).
\end{abstract}

\section{OBSERVATION AND RESULTS}

In the 3 years of study period from January 2002 to December $2004,13,822$ biopsy materials were received. Of these, the thyroid lesions accounted for 782 cases. Hence, the overall incidence of thyroid lesions is $5.65 \%$. The number of neoplastic thyroid tumours were 326 . Of these, 224 were benign (68.71\%) and 102 cases were malignant (31.28\%).

The number of benign and malignant thyroid tumours was 65 and 60 respectively. 
Thus, the incidence of malignant tumours of the thyroid is $46.2 \%$ compared to the incidence of benign thyroid tumours, which is $50 \%$.

\section{Age Incidence}

While the benign thyroid tumours had a peak incidence in the third decade, the peak incidence of malignant thyroid tumours was seen in fourth decade. The youngest patient was 5 yrs. of old. The oldest patient was 89 yrs. of old.

\section{Sex Distribution}

Of the total 782 thyroid tumours, 700 cases occurred in females (incidence $89.5 \%$ ) whereas as only 82 cases $(10.5 \%)$ occurred in males. The average age at diagnosis among male patients was $47 \mathrm{yrs}$. whereas in female it was $36 \mathrm{yrs}$.

\section{Clinical Presentation}

The duration of thyroid swelling was evaluated and it is tabulated in table (1). $84.5 \%$ of the patients had thyroid swelling with duration less than 1 year. $15.5 \%$ of the patient had thyroid swelling with a duration of more than 2 yrs. Clinically, the thyroid gland was enlarged diffusely in 20 cases while the rest (122) had nodular enlargement. The size of the nodule varied from $2 \times 0.5 \mathrm{~cm}$ to $10 \times 5 \mathrm{cms}$.

\section{Cytological Evaluation of Thyroid Neoplasm}

During the study period, 3489 smears were received for cytological examination. Out of these, 763 were FNAC of thyroid. Of these, only 152 cases had a postsurgical followup details. Of all the 152 cases subjected to FNAC, smears were found to be unsatisfactory/inadequate in about 15 cases.

A range of cytological diagnosis was offered on all satisfactory smears as shown in table 2 . The table also depicts the number of cases in each entity with its percentage of incidence. Table 3 depicts the comparison of cytological diagnosis offered in the present study with those reported by various authors.

\section{Histopathological Analysis}

Of the 152 cases on which fine needle aspiration cytology was performed, histopathological correction was possible for all the 130 cases.

The most common benign lesion encountered was follicular adenoma. One case of hyalinising trabecular adenoma and another case of macrofollicular adenoma were reported.

The next more common was papillary carcinoma (33.0\%). 11 cases of follicular carcinoma $8.46 \%$ were countered during the study period.

\section{Correlation between Cytological and Histopathological Diagnosis}

Table 4 illustrates correlation obtained between cytological and histopathological diagnosis. There was an excellent correlation in cases of papillary carcinoma thyroid (88.37\%) and anaplastic carcinoma of thyroid (100\%). 15 cases where a cytological diagnosis of suspicious of malignancy was offered in which 2 cases turned out to be medullary carcinoma, 4 cases of papillary carcinoma, and 6 cases of follicular carcinoma was offered. 1 case of each poorly-differentiated carcinoma and spindle cell sarcoma offered.

One case of indeterminate malignancy was offered. Of the 54 cases where a cytological opinion of follicular neoplasm was offered, 42 cases (64.61\%) turned out to be of follicular adenoma, while 3 were follicular carcinoma, only one case of squamous cell carcinoma was reported and 2 cases of indeterminate malignancy was offered. 2 cases were turned out to be of Hashimoto's thyroiditis and 4 cases are of multinodular goitre.

\section{Sensitivity and Specificity}

Out of the total 152 cases analysed, the cytological diagnosis benign and malignant smears were 54 and 41 respectively. The following values were deduced from table 2 for benign lesions.
1. True positive $=54$
2. False positive $=1$
3. True negative $=3$
4. $\quad$ False negative $=2$

Sensitivity $=$ Number of true positive $\mathrm{x} 100$

Number of true positive+

Number of false negative

$54 \times 100$

\begin{tabular}{|c|c|c|}
\hline Duration & Number of Cases & Percentage (\%) \\
\hline <3 months & 21 & 16.1 \\
\hline 4-6 months & 42 & 32.3 \\
\hline $\begin{array}{c}\text { 7 months-1 } \\
\text { year }\end{array}$ & 47 & 36.1 \\
\hline 1-2 years & 18 & 13.8 \\
\hline 3-5 years & 2 & 1.5 \\
\hline \multicolumn{2}{|r|}{ Table 1: Clinical Duration of Swelling } \\
\hline
\end{tabular}

\begin{tabular}{|c|c|c|}
\hline FNAC Diagnosis & $\begin{array}{c}\text { Number of } \\
\text { Cases }\end{array}$ & $\begin{array}{c}\text { Percentage } \\
\text { (\%) }\end{array}$ \\
\hline Follicular Neoplasm & 54 & $35.5 \%$ \\
\hline Follicular Carcinoma & 2 & $1.3 \%$ \\
\hline Papillary Carcinoma & 33 & $21.7 \%$ \\
\hline $\begin{array}{c}\text { Anaplastic } \\
\text { Carcinoma }\end{array}$ & 1 & $0.65 \%$ \\
\hline Suspicious & 20 & $13.25 \%$ \\
\hline Nonneoplastic & 27 & $17.8 \%$ \\
\hline Unsatisfactory & 15 & $9.96 \%$ \\
\hline Table 2: Cytological Diagnosis and Number of Cases of \\
\multicolumn{3}{|c|}{ Thyroid FNAC } \\
\hline
\end{tabular}




\begin{tabular}{|c|c|c|c|c|c|}
\hline Author/Year & No. of Cases & Benign & Malignant & Suspicious & Unsatisfactory \\
\hline Friedman et al (1979) & 265 & $178(67.16 \%)$ & $63(15.3 \%)$ & $123(29.85 \%)$ & - \\
\hline Ghoshal et al (1984) & 75 & $58(77.33 \%)$ & $17(22.67 \%)$ & - & - \\
\hline Pandit et al (1986) & 80 & $64(80 \%)$ & $8(10 \%)$ & $3(3.75 \%)$ & $1(1.25 \%)$ \\
\hline Suparna et al (1998) & 103 & $88(85.43 \%)$ & $6(5.82 \%)$ & $1(0.97 \%)$ & $3(2.93 \%)$ \\
\hline Shilpa et al (2000) & 141 & $83(58.8 \%)$ & $7(4.9 \%)$ & $6(4.3 \%)$ & $11(7.9 \%)$ \\
\hline Current Study & 141 & $51(36.17 \%)$ & $40(28.36 \%)$ & $14(9.92 \%)$ & $20(14.18 \%)$ \\
\hline
\end{tabular}

\begin{tabular}{|c|c|c|c|c|c|c|c|c|c|c|c|c|}
\hline FNAC & $\begin{array}{l}\text { No. of } \\
\text { Cases }\end{array}$ & $\begin{array}{l}\text { Hashimoto's } \\
\text { Thyroiditis }\end{array}$ & MNG & $\begin{array}{c}\text { Foll. } \\
\text { Adenoma }\end{array}$ & $\begin{array}{c}\text { Foll } \\
\text { Ca }\end{array}$ & $\begin{array}{c}\text { Pap } \\
\text { Ca }\end{array}$ & $\begin{array}{c}\text { Medullary } \\
\text { Ca }\end{array}$ & \begin{tabular}{|c|} 
Anaplastic \\
Ca
\end{tabular} & $\begin{array}{c}\text { Poorly } \\
\text { Ca }\end{array}$ & $\begin{array}{l}\text { Spi } \\
\text { Ca }\end{array}$ & SCC & UND \\
\hline Unsatisfactory & 13 & & & 10 & & 1 & & & & & & 2 \\
\hline Follicular Neo & 54 & 2 & 4 & 42 & 3 & & & & & & 1 & 2 \\
\hline Folli Ca & 2 & & & & 2 & & & & & & & \\
\hline Pap Ca & 38 & & & & & 38 & & & & & & \\
\hline Anapl & 1 & & & & & & & 1 & & & & \\
\hline Suspic & 15 & & & & 6 & 4 & 2 & & 1 & 1 & & 1 \\
\hline Nonneo & 13 & & & 13 & & & & & & & & \\
\hline
\end{tabular}

\begin{tabular}{|c|c|c|c|}
\hline Author & Sensitivity & Specificity & Accuracy \\
\hline Suparna et al & $83.33 \%$ & $100 \%$ & $96.77 \%$ \\
\hline Ghoshal et al & $71.33 \%$ & $96.2 \%$ & $94.01 \%$ \\
\hline Shilpa R Karwa & $66.66 \%$ & $96.9 \%$ & $94.28 \%$ \\
\hline Current Study & $95.35 \%$ & $83.35 \%$ & $92.72 \%$ \\
\hline \multicolumn{4}{|c|}{ Table 5: FNAC-A Comparative Study } \\
\hline
\end{tabular}

\begin{tabular}{|c|c|c|c|c|}
\hline Author (Year) & $\begin{array}{c}\text { Total } \\
\text { Cases }\end{array}$ & Females & Males & F:M \\
\hline Rao et al (1971) & 241 & 198 & 43 & $4.6: 1$ \\
\hline $\begin{array}{c}\text { Baldwin et al } \\
(1978)\end{array}$ & 129 & 103 & 26 & $3.9: 1$ \\
\hline $\begin{array}{c}\text { Bhansali et al } \\
(1982)\end{array}$ & 600 & 462 & 138 & $3.3: 1$ \\
\hline $\begin{array}{c}\text { Suparna et al } \\
(1998)\end{array}$ & 103 & 78 & 25 & $3.1: 1$ \\
\hline $\begin{array}{c}\text { Shilpa et al } \\
(2000)\end{array}$ & 141 & 126 & 15 & $8.4: 1$ \\
\hline Current Study & 152 & 142 & 10 & $9: 1$ \\
\hline \multicolumn{7}{|c|}{ Table 6: Sex Incidence-A Comparative Study } \\
\hline
\end{tabular}

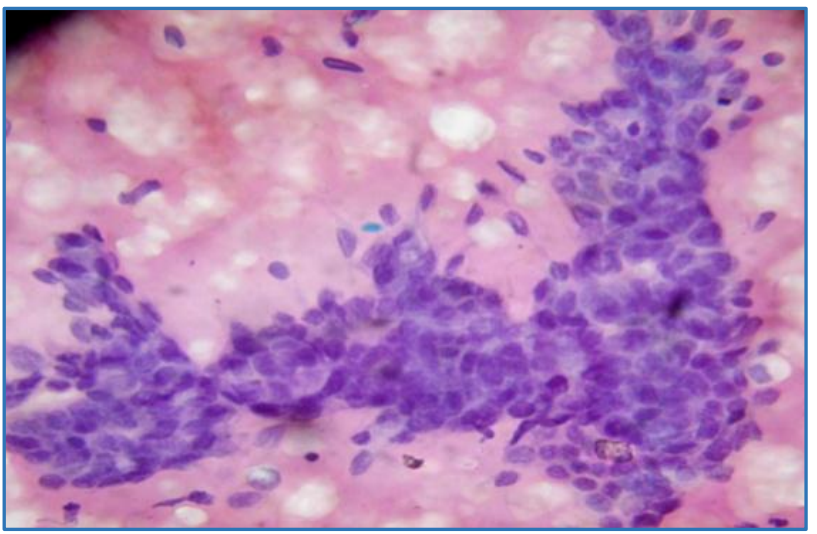

Fig. 1: Clusters of Thyroid Follicle with Nuclear Grooving in FNAC Smear

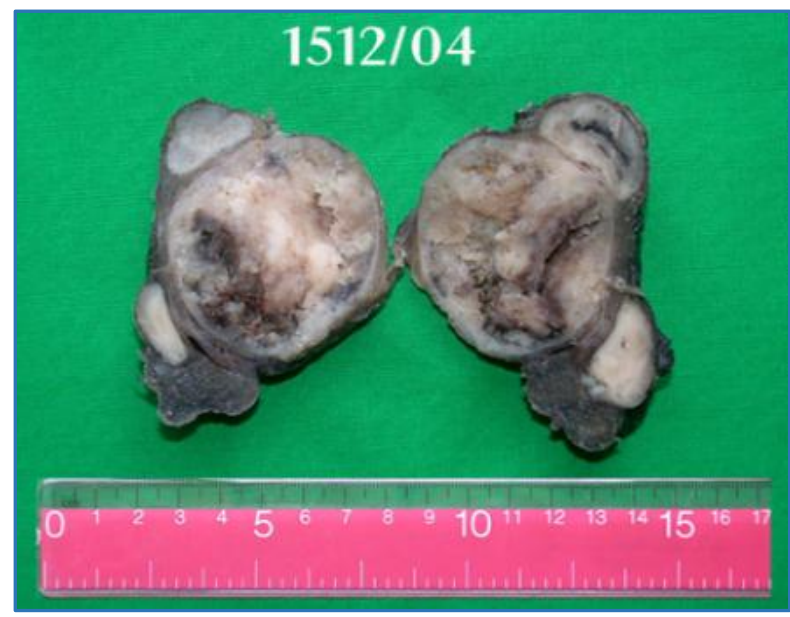

Fig. 2: Shows Gross Appearance of Follicular Adenoma. C/S Showing Well-Circumscribed Single Nodule-

Path No.1512/04

\section{DISCUSSION}

Recently, FNAC has become the investigation of choice in thyroid swelling or neck swelling thought to be of thyroid origin. FNAC is considered to be safe, inexpensive, and less invasive in nature. It has excellent patient compliance, simple, and quick to perform in the outpatient department. ${ }^{2}$ FNAC of the thyroid is the single most effective test for the preoperative diagnosis of solitary thyroid nodule. The modern use of the technique originated in Scandinavian in the 1950s and 1960s.

Most cases in the present study were in the 3rd and 4th decade. This is in accordance with study of Rao SK et al (1971), Bhansali et al (1982), and Suparna et al (1998). In the present study, there is an obvious female preponderance comprising $89.5 \%$ of the total with a female:male ratio of $8.5: 1.5$. Table 6 , shows the comparison of sex distribution with other series. All the studies have consistently shown an increased incidence in female population. Table 5 and 6 shows a comparative study of FNAC and Sex incidence.

\section{Clinical Presentation}

Patients with thyroid diseases usually seek medical interventions for the following complaints viz., swelling in the 
neck, pain, sudden increase in size, and hoarseness of voice, etc.

In our study, most of the patients complained of a thyroid swelling of less than 1 year duration. A few apparently noticed a sudden increase in size in a previously enlarged thyroid gland. Aspiration from these cases usually yielded haemorrhagic material or fluid.

On palpitation, the thyroid was either diffusely enlarged or had a nodular presentation. ${ }^{3}$ The size of the nodules in our study had a mean diameter of $3.8 \pm 2 \mathrm{~cm}$, a finding consistent with those reported by Rao et al and Suparna et al, i.e. 2.5 to 3 $\mathrm{cm}$ and 2.5 to $4 \mathrm{~cm}$ respectively.

\section{Fine Needle Aspiration Cytology-Assessment and Diagnosis}

The FNAC has become in a matter of few years an extremely popular technique for the evaluation of thyroid diseases especially of solitary thyroid nodules. It has sidelined the use of core needle biopsy as most authors are reluctant to use the latter because of a small, but definite risk of complications (Bleeding, nerve injury, tracheal perforation, tumour implantation).

Preoperatively, FNAC was performed in 152 patients. Of these, only 110 cases yielded a cellular aspirates of which 52 cases $(35.5 \%)$ were reported as follicular neoplasm and 36 cases $(23.6 \%)$ were positive for malignancy the remaining 20 cases $(13.25 \%)$ were suspicious of malignancy.

\section{Follicular Neoplasm}

According to Atkinson et al (1986), the cytological features include cellular smear, many equal-sized epithelial cell clusters, syncytial cell aggregates, nuclear crowding, microfollicles, and rosette like groupings without lumen and scanty or no colloid. 4

The cytological appearances of follicular adenoma and follicular carcinoma are very similar. Those include, a cellular smear with many equal-sized cell clusters scattered throughout the smear with a scarce or absent colloid. Since, the ultimate difference between the two entities lies in the demonstration of capsular/vascular invasion in cases of follicular carcinoma, it is very difficult to separate the two cytologically. However, both smears are cellular composed of syncytial clusters of crowded cells, but carcinoma cells tends to have larger nuclei, more prominent nucleoli, and coarser and more irregular chromatin. These features are described by Kini et al 1996.

In 1979 Lowhagen $\mathrm{T}$ et al described in aspiration cytology from the nodules of the thyroid, 70\%-90\% of the follicular neoplasms are detected by cytology and the proportion of carcinoma designated as follicular neoplasm ranges from 14$44 \%$ in large series . In the present study, $3.70 \%$ of follicular carcinoma diagnosed out of 54 follicular neoplasm. In two cases, a cytological diagnosis of follicular carcinoma was offered. Because in addition to the cytological findings described above, there was hypercellularity and increased nuclear pleomorphism with a definitive infiltration into adjacent tissues on clinical examination.

\section{Papillary Carcinoma}

According to Sodarstrom and Bjorklund et al in 1973, the features of papillary carcinoma with intranuclear cytoplasmic inclusions are described. As papillary clusters are the most characteristic features of papillary carcinoma,5,6 because the needle may not remove papillae intact. Features that are considered pathognomonic of papillary carcinoma are follows.

1. Increased cellularity.

2. Papillary fronds with well-defined margins.

3. Nuclear grooves/inclusions.

4. Thin powdery nuclear chromatin.

5. Prominent nucleoli.

6. Thick, scanty, chewing gum colloid.

7. Psammoma bodies.

(Fig. 1) shows papillary carcinoma cytological picture .In our present study, we encountered 35 cases of papillary carcinoma, thyroid smears in FNAC, tight clusters of tumour cells seen in $20 \%$ cases, thick chewing gum colloid in one case, and nuclear inclusions seen in $5 \%$ of the cases.

\section{Other Malignancies}

Only one case of anaplastic carcinoma of thyroid was seen where the smears showed an isolated cells and in tissue fragments extremely pleomorphic in size and shape; small-togiant forms; nucleus large, bizarre shapes; clumped chromatin with excessive parachromatin clearing; nucleoli large, cytoplasm abundant, pale, vacuolated, or dense.

\section{Histopathological Followup and Correlation}

Histopathological correlation could be obtained in 130 cases where thyroidectomy was performed. Table 4 illustrates the various types of thyroid lesions encountered in our study, while table 6 depicts the correlation obtained between the diagnosis outlined given in the "WHO histological typing of thyroid tumours" has been adopted in this study.

As was evident on cytology, the most common lesion on histopathology also proved to be a follicular adenoma with varying amount of haemorrhage, cystic degeneration, and calcification.

\section{Follicular Adenoma}

Adenomas are benign encapsulated tumour and are almost always solitary. Grossly, they are characteristically surrounded by a thin capsule that is grossly and microscopically complete shown in Fig. 2 secondary degenerative changes such as haemorrhage, cystic degeneration, oedema, fibrosis, calcification, and bone formation. In our study, 15 cases of cystic degeneration, 12 cases of haemorrhage, and 10 cases of calcification were noted. In the present study, one case of hyalinising trabecular adenoma had been reported. 7

Hyalinising trabecular adenoma first described by Carney et al 1987 and also referred to as "paraganglioma-like adenoma" of thyroid as described by Bronner MP et al in 1988, is a distinctive, but uncommon subtype of follicular adenoma with a female preponderance. These tumours generally behave in a benign fashion. ${ }^{8}$ One case of macrofollicular adenoma had been reported histopathologically. ${ }^{9}$

\section{Papillary Carcinoma}

Papillary carcinoma the most common neoplasm of the thyroid comprises about $60 \%$ of all thyroid carcinoma. It occur more frequently in women with a female:male ratio of $3: 1$. Papillary carcinoma is seen in all age group with peaks in the third decade. 
The gross appearance of papillary carcinoma varies with size, large tumours are typically fleshy, velvety, profile, and may extend to the capsule. They are non-encapsulated, but have a tendency to develop fibrosis that results in partial encapsulation. Cystic changes due to degeneration are very common as is calcification. This is the most easily identifiable malignancy on FNAC. We had diagnosed 33 cases $(21.7 \%)$ on cytology, but surgical followup was available for all the cases, which was consistent with histopathology. The overlapping of nuclei and ground-glass appearance was more clearly seen only on histopathology.

\section{Other Malignant Lesions}

In the present study, we diagnosed two cases of medullary carcinoma on histopathology.10,11,12 For the 2 cases, FNAC diagnosis were not available. The other cases, 4 cases were diagnosed as follicular neoplasm had been reported histopathologically as each case of anaplastic carcinoma, ${ }^{13}$ poorly-differentiated carcinoma, ${ }^{14,15}$ primary squamous cell carcinoma, and spindle cell sarcoma.

\section{Diagnostic Accuracy}

Reports regarding the sensitivity and specificity of FNAC of the thyroid are confused by 2 factors.

1. Most studies have not correlated results with specific histologic classification of the neoplasm.

2. The term "follicular neoplasm" is not standardised.

Figures on nonneoplastic conditions are difficult to evaluate because of the lack of histological verification. The term "follicular neoplasm" is ambivalent in usage. Atkinson et al preferred to apply this phrase to cellular colloid nodules, follicular adenomas, and well-differentiated follicular carcinoma whenever there is a cell rich monomorphic aspirate composed of follicular cells.

\section{SUMMARY AND CONCLUSION}

In this study,

1. The maximum number of patients with thyroid neoplasm were in their third and fourth decades. Thyroid diseases are rare in the first decade and beyond the seventh decade.

2. There was a definitive female preponderance with females out numbering males in the ratio of 8.5:1.5.

3. The mean age at diagnosis among male patients was 47 years while it is 37 years in females.

4. The most common symptom was that of a swelling in the neck region. Of which, $82 \%$ had the swelling less than one year in duration.

5. Majority of the cases show the thyroid gland had a nodular enlargement with the mean nodule diameter was found to be $3.8 \pm 2 \mathrm{cms}$.

6. The $9.9 \%$ of the smears were considered unsatisfactory or inadequate where a cytological diagnosis could not be offered. $36.17 \%$ of the patient had evidence of benign lesion on cytology whereas only $28.36 \%$ had a definite evidence of malignancy. 20 cases were suspicious of malignancy.
7. In histopathological analysis, the maximum number $(34.5 \%)$ to be follicular adenoma. Next common tumour encountered were papillary carcinoma.

8. The current study has shown that in our centre FNAC has a sensitivity of $96.42 \%$ for benign lesions and $95.35 \%$ for malignant lesions. The accuracy for benign lesions 92.72\% and malignant $95.34 \%$.

\section{REFERENCES}

1. Charry AK. Role of fine needle aspiration biopsy in thyroid swellings. Indian Journal of Surg 1983;113:346-9.

2. Abele JS, Miller TR. Fine needle aspiration of the thyroid nodule: clinical applications. In: Clarke OH. edr. Endocrine surgery of thyroid and parathyroid glands. St. Louis Mosby 1985:293-335.

3. Busseniers AE, Oertel YC. Cellular adenomatoid nodules of the thyroid: review of 219 fine needle aspirates. Diagnostic Cytopathology 1993;9(5):581-9.

4. Atkinson B, Ernest CS, Li Volsi V. Cytology diagnosis of follicular tumours of the thyroid. Diagnostic Cytopathol 1986;2:1-5.

5. Chen KTK, Rosai J. Follicular variant of thyroid papillary carcinoma-a clinicopathologic study of 6 cases. Am J Surg pathol 1977;1(2):123-39.

6. Carcangiu MR, Zampi G, Pupi A, et al. Papillary carcinoma of the thyroid. A clinicopathologic study of 241 cases treated at the University of Florence, Italy. Cancer 1985;55(4):805-28.

7. Carney JA, Ryan J, Goellner JR. Hyalinising trabecular adenoma of the thyroid gland. Am J Surg pathol 1987;11(8):583-91.

8. Hawkins F, Bellido D, Bernal C, et al. Fine needle aspiration biopsy in the diagnosis of thyroid cancer and thyroid disease. Cancer 1987;59(6):1206-9.

9. Hazard JB, Kenyon R. A typical adenoma of the thyroid. AMA Arch Pathol 1954;58(6):554-63.

10. Mendonca ME, Ramos S, Soaver J. Medullary carcinoma: a revaluation of the cytologic criteria of diagnosis. Cytopathology 1991;2:93-102.

11. Hales M, Rosenau W, Okerlund MD, et al. Carcinoma of the thyroid with a mixed medullary and a follicular pattern: morphologic, immunohistochemical, and clinical laboratory studies. Cancer 1982;50(7):1352-9.

12. Holm R, Sobrinho-Simoes M, Nesland JM, et al. Medullary carcinoma thyroid with thyroglobulin immunoreactivity. A special entity? Lab Invest 1987;57(3):258-68.

13. Nel CJ, Van Heerden JA, Goellner JR, et al. Anaplastic carcinoma of the thyroid: a clinicopathologic study of 82 cases. Mayo Clin Proc 1985;60(1):51-8.

14. Carciangiu ML, Zawyri G, Rosai J. Poorly-differentiated ("insular") thyroid carcinoma. A reinterpretation of Langhans "wuchernde struma". AM J surg pathol 1984;8(9):655-68.

15. Calmettes C, Caillou B, Moukhtar MS, et al. Calcitonin and carcinoembryonic antigen in poorly-differentiated follicular carcinoma. Cancer 1982;49(11):2349-8. 